\title{
An Analysis of Article Errors among Saudi Female EFL Students: A
} Case Study

\author{
Maha Alhaysony ${ }^{1}$ \\ ${ }^{1}$ Department of English, University of Ha'il, Saudi Arabia \\ Correspondence: Maha Alhaysony, Department of English, University of Ha'il, Saudi Arabia. E-mail: \\ m.alhaysony@gmail.com
}

Received: May 17, 2012 Accepted: June 9, 2012 Online Published: September 20, 2012

doi:10.5539/ass.v8n12p55

URL: http://dx.doi.org/10.5539/ass.v8n12p55

\begin{abstract}
This study aims at providing a comprehensive account of the types of errors produced by Saudi female EFL students in their use of articles, based on the Surface Structure Taxonomies (SST) of errors. Data were collected from written samples of 100 first-year female EFL students at the Department of English in the University of Ha'il. Students were given one-and-a-half hours to write on one of six different descriptive topics related to their life and culture. Analysis of errors in students' written samples revealed that while students made a considerable number of errors in their use of articles according to SST, omission errors were the most frequent, while substitutions were the least frequent. Additionally, among all types of omission errors identified, the omission of the indefinite article 'a' was the most frequent. In sharp contrast, the omission of the indefinite article 'an' was the least frequent error. Not surprisingly, errors relating to the addition of the definite article 'the' were the most frequent, which correlates with the fact that the definite article is used more widely in the Arabic language than in English. In fact, the English article system is a complex aspect of English grammar. It is one of the most difficult areas of acquisition for even the most advanced learners who have perfectly learnt all other features of the language. This means that EFL instructors may tolerate these errors and look at article errors as more serious.

Further, results showed that Arabic interference was not the only source of errors, but that English was a source of many errors as well. Findings showed that $57 . \%$ of the errors were interlingual ones, indicating the influence of the native language. Thus, interlingual errors are the most commonly occurring types. On the other hand, intralingual errors represented $42.56 \%$ of article errors. This result also indicates that L1 interference strongly influences the process of second language acquisition of the articles, having a negative effect on the learning process. Teachers and instructors should therefore point out more clearly the differences between L1 and L2 in the use of articles.
\end{abstract}

Keywords: intralingual, surface structure taxonomies, articles, omission, addition, substitution

\section{Introduction}

Within the field of second language research (SLR), a large number of studies have focused on error analysis. In general terms, errors have long held the fascination of language instructors and researchers. According to Corder (1967) errors were considered a problem that should be eradicated as soon as possible. However, errors are now looked on as adevice that can assist in the learning process. They provide evidence of the learner's level in the target language, as stated by Gass and Selinker (1984). Moreover, AbiSamra (2003) pointed out that errors also contain valuable information on the learning strategies of learners. Richards (2002) mentioned that in the speaking or writing of a second or foreign language, an error is the use of a linguistic item (e.g. a word, grammatical item, speech act, etc.) in a way which a fluent or native speaker of a language regards as faulty or incomplete. Thus, conducting error analysis is one of the best ways of describing and explaining errors made by ESL/EFL learners. This kind of analysis can reveal the sources of these errors and the causes of their frequent occurrence. Once the sources and causes are exposed, it will be possible to determine the remedy, as well as the emphasis and sequence of future instruction.

Error analysis is very important for learners and teachers. Hasyin (2002) observed that errors are advantageous for both learners and teachers. It provides information to the teachers on students errors. This helps the teachers in three ways, firstly to correct their errors, secondly to improve their teaching and thirdly to focus on those area that need reinforcement. Coder (1967) described that analysis of learners errors provide insight into the innate 
nature of learners learning system and process of language teaching.

As an English language teacher, the researcher is aware that Saudi students in general and in the University of Ha'il in particular commit errors in English writing. Therefore, this study investigates errors produced by Saudi female EFL students in their use of articles, based on the Surface Structure Taxonomies (SST) of errors. It is hoped that this study will provide an insight and means to EFL teachers andlearners to recognize the importance of the error types in the use of the article system by Saudi students at Ha'il University in Saudi Arabia and to develop guidelines for correction and improvement of writing skills. To the best of my knowledge, this is the first study of its kind that investigates the misuse of the article system by Saudi female students.

\section{Literature Review}

Research on second language acquisition has witnessed revolutionary advancements since the publication of Fries' book Teaching and Learning English as a Foreign Language in 1974. Since then, various studies have been conducted to account for the process of L2 acquisition in many languages around the world. Close consideration of the linguistic research dedicated to this topic shows that most of the studies carried out so far have been fundamentally based on either the Contrastive or Error Analysis approaches. Contrastive Analysis (CA) is rooted in behaviourism and structuralism (Magnan, 1983). Furthermore, Mourtaga (2004) describes CA as a type of linguistic research that argues that the problem in learning a second language is the interference from the source language. In contrast, Error Analysis (EA) is a type of linguistic analysis that focuses on errors committed by learners (AbiSamara, 2003). Error Analysis has drawn the attention of linguists and has become an important part of applied linguistics, since its recognition in the 1970s . Instead of looking at learners' errors only, EA looks at the learner and the language being learned (Magnan, 1983). Further, Magnan summarized the most important outcome of EA in the following words: '... we now view language learning as a series of stages or interlanguages, and errors as positive evidence that learners are experimenting with linguistic rules in order to progress from one interlanguage stage to the next' (p. 383).

In his study of syntactic errors made by first-year Sudanese University students, Kambel (1980) shows that students' errors in verb phrases are of three types, viz., verb formation, tense, and subject-verb agreement. Zughul (1991) identified errors of lexical choice made by a sample of Arabic speaking learners of English. The participants were 128 English Department students at Yarmouk University in Jordan. He found 691 lexical errors. He concluded that a large number of problems may be predicted by contrastive analysis, but error analysis is more realistic because not all predicted errors occur. Zughul suggested what he called a 'problematic word list' as a useful way for learning a foreign language, which helps learners adopt practical strategies for improving their semantic competence. Another study, dealing with Japanese learners of English, was undertaken by Mizuno (1999), who focused solely on errors in the use of English articles. Results revealed that Japanese learners selected articles according to semantic, formal, and phonetic criteria. The results also indicated that L1 interference strongly influences the process of second language acquisition of the articles. The author concludes that one should teach the definite article first, as it is the most unmarked and the most frequent, giving more attention to the zero article and to the pragmatic-semantic domain, exposing learners to authentic and meaningful English and to comprehension activities, and presenting the core meaning of each article in comparison with Japanese.

Khuwaileh and Shoumalia (2000) conducted a study on Jordanian students in both Arabic and English in order to examine their writing errors. They found that learners made different types of errors; the most frequent were lack of cohesion and coherence, and tense errors. In the aim of investigating the use of English prepositions, Lakkis and AbdelMalak (2000) conducted a study on 55 Arabic university students. Results showed that in general all students made similar errors in which they relied on transfer to judge the appropriate usage of prepositions. They recommended that instructors point out differences between L1 and L2 in the use of prepositions.

In his detailed article on Arabic speakers, Smith (2001) pointed out many examples of errors that Arabic learners of English might commit. Among these errors, for instance, were mistakes in consonant clusters, word order, questions and negatives, auxiliaries, pronouns, time, tense and aspect, modal verbs, articles, etc. As for articles, he stated that 'the indefinite article causes the most obvious problems as it is commonly omitted with singular and plural countables' (p. 205). In his attempt to examine acquisition of the English article system by Japanese students with varying levels of proficiency, Butler (2002) concludes that the higher the students' levels of proficiency were, the more target-like usage they could achieve, while lower proficiency learners were strongly influenced by a set of rules that they believed were given by teachers, textbooks, and so on.

AbiSamra (2003) collected samples of written work from 10 students in grade 9. The author classified the writing errors detected into five categories: grammatical (prepositions, articles, adjectives, etc.); syntactic 
(coordination, sentence structure, word order, etc.); lexical (word choice); semantic and substance (punctuation, capitalization, and spelling); and discourse errors. Results revealed that one third of the students' errors were transfer errors from the native language, and the highest numbers of errors were in the categories of semantics and vocabulary. The rest of the errors (64.1\%) were errors of over-application of the target language, the highest numbers of errors being found in substance (mainly spelling), syntax and grammar. In order to reduce the errors, AbiSamra recommended encouraging students to speak English at home and with their friends, as well as teaching more effectively the rules and conventions of writing.

Snape (2005) conducted a study on Japanese and Spanish learners of English. Snape found that they differ in their use of the L2 article system in that Spanish learners of English replace indefinite articles for definite ones or vice versa, and that Japanese learners have a 'mapping problem' rather than a representational deficit, while Spanish learners have neither (p. 159). In another study, by analyzing the written compositions of a number of Jordanian English language students, Bataineh (2005) classifies different types of errors in the use of indefinite articles. She claims that among all types of errors identified only the deletion of the indefinite article could be attributed to L1 interference.

Bukhari and Hussain (2011) conducted a study to investigate the errors of Pakistani students inprepositions and articles. The main focus of the study was to analyse the errors of students in articles and prepositions. They found that that the total number of errors made by students on the measure of articles was 152 . Out of which (127) $83.56 \%$ was observes in indefinite articles and (25) $16.44 \%$ was observed in definite articles. They also found that $52.63 \%$ of the totalerror was omission errors, $19.08 \%$ was insertion errors and $28.29 \%$ was confusion errors. The results also revealed that Pakistani students faced more difficulties in learning indefinite articles in their writings.

The analysis of error sources has been regarded as a central aspect in the study of learner errors. Researchers believe that the clearer the understanding of the sources of learners' errors, the better second language teachers will be able to assist the process of L2 learning. In their study, Dulay and Burt (1974) categorized these errors into three groups: interference, intralingual, and unique errors. According to their study only $5 \%$ of the errors were interference while $87 \%$ were intralingual and $8 \%$ were unique. They concluded that children do not use their L1 habits in the process of learning a new language. Further, Kim (1987) conducted a study in the field of error analysis among 12th grade Korean English learners in their composition and reported that intralingual errors occurred more than interlingual.

Another study was conducted by Brown (1994). He found that at the early stages of language learning, a large number of errors occur due to negative transfer. His study showed that as language learners develop their English, intralingual errors overtake interlingual errors. The interlanguage of Arabic students of English as a second/foreign language has also been the subject of a great quantity of studies since the 1970s. Scott and Tucker, cited in Frith (1977), describe an interesting error analysis of oral and written samples of 22 Arab-speaking EFL students at the American University of Beirut. They concluded the following:

1) For these students, native language interference was a persistent problem in the use of prepositions and articles.

2) The nature of the corpus led the researchers to posit a rule-governed interlanguage system which was changed and reorganized during the term. They state that we may say we were dealing with two approximate systems, the second being a closer approximation than the first to adult native English.

In his attempt to investigate the sources of errors in the performance of Jordanian students at post-secondary stage, Mukattash (1978) claims that only $23 \%$ of errors can be attributed to the L1.

\subsection{The Article Systems in the Arabic and English Languages}

Before presenting a detailed discussion of the results, it is highly important to make clear that English and Arabic are very different languages from two different language families. 'Arabic belongs to the Semitic group of languages. More specifically, it is an off-shoot of the language of South-West Arabia, while English is an Indo-European language' (El-Sayed, 1982, p. 180-181). Therefore, the grammatical structure of Arabic is different from that of Indo-European languages such as English. As a matter of fact, these differences were the cause of many errors made by the students. The differences and similarities between Arabic and English in terms of their article systems should therefore be clarified.

There are three different articles in English, the definite article 'the', the indefinite article ' $a$ ' or 'an', and the zero article ' $\varnothing$ '. According to Quirk et al. (1972), 'the' is used with specific nouns, 'a' or 'an' is used with non-specific nouns in the singular, while ' $\varnothing$ ' is used with non-specific nouns in the plural, proper nouns, mass nouns, abstract 
nouns, and non-count nouns, such as 'rice', 'water', etc.

Nouns used in English might appear in one of three forms:

1) Singular with 'a/an'; e.g. A horse is a useful animal.

2) Singular with 'the'; e.g. The horse is a useful animal.

3) Plural with zero 'ø'; e.g. Horses are useful animals.

(Kharama \& Hajjaj, 1989)

Furthermore, they pointed out that an article might modify two nouns conjoined by 'and' if they represent one unit such as 'the father and mother', 'the bread and butter' etc.

In Arabic, the article system is completely different from that of English. While there are three in English, Arabic has only two, the definite article ' $a l$ ', which is a prefix, and the zero or indefinite article, which is simply the absence of the definite article. Regarding the use of the definite article, the main difference between English and Arabic is that Arabic often uses the definite article in contexts where English does not. Kharama and Hajjaj (1989) give some examples as follows:

1) Nouns used generically in Arabic, whether singular or plural, take 'al' (the).

2) Abstract nouns in Arabic take 'al', more frequently than in English.

3) When a mass noun refers to the whole kind, it takes 'al'.

4) Some proper nouns take 'al', such as 'al-kahera' (*the Cairo).

5) When two nouns are joined by 'and', 'al' is repeated even when these nouns represent one unit such as 'al-zawjuwa al-zawjatu' (*the husband and the wife).

6) In some idiomatic forms such as:

A 'malufii Al-lailiwa al-nahaari. $=*$ I work in the day and the night.

Thus, these are the reasons why Arabic learners overuse the definite article when they write in English and make numerous interlingual/interference errors.

\subsection{Research Question}

From a general overview of literature, it is clear that errors are committed widely by ESL/EFL learners. To investigate the different types of errors regarding articles whichSaudi female EFL students make and the sources (causes) of these errors, the researcher of the present study raised the following research questions:

1) What are the types of article errors among Saudi female students enrolled in English writing classes?

2) What are the possible sources of these errors?

\section{The Present Study}

\subsection{Overview}

In the light of the preceding discussion, this paper is devoted to investigating the misuses of the English articles by Saudi female EFL students. A number of analytical procedures are used to analyze the data:

1) Identifying the deviant forms. This was carried out by a detailed analysis of the output.

2) Analyzing and classifying errors found in the use of the articles.

3) Establishing a frequency count of such errors and the sources of the errors.

\subsection{Participants}

The participants in this study were 100 female students enrolled on the second semester of the first year at the English Department of Ha'il University. This means that they had studied Writing Composition 1, which focuses on sentence and paragraph writing. All the subjects were selected randomly from those willing to participate. The participants' academic levels were almost the same since all of them were admitted to the university according to a fixed graduate point average (GPA) in their general secondary certificate.

\subsection{Instrument of Data Collection}

\subsubsection{Written Sample}

The participants were asked to write a well-organized essay on one of six familiar topics. They were asked to write approximately 150 to 300 words. The suggested topics were 

1) The Saudi family
2) A popular Saudi dish
3) My country
4) Shopping
5) My home
6) Summer holiday

\subsubsection{Procedure}

The written samples were collected from 100 female students enrolled on the second semester of the first year at the English Department of Ha'il University. The students were selected randomly from about 300 students who had indicated their willingness to participate. They were given a full class period, about one hour and a half, to write 150 to 300 words on one of the previously mentioned topics. The researcher herself analyzed the written samples, focusing on article errors and ignoring all other errors.

\subsection{Data Analysis}

The researcher classified errors according to the Surface Structure Taxonomy of errors (SST), namely, substitution, omission, and addition, recording the frequency of each error type and the percentage of the total. Furthermore, students' errors were classified according to their possible sources into interlingual and intralingual, showing the frequency of errors according to their source. In other words, in the analysis of the written samples, the researcher employed two methods: contrastive analysis to identify interlingual errors (errors of L1 interference) and error analysis to identify intralingual errors (errors which have nothing to do with L1 interference).

\section{Results and Discussion}

In determining and analyzing students' errors, the researcher followed the following steps identified by Ellis (1997):

Collecting data $\rightarrow$ Identifying errors $\rightarrow$ Classifying errors $\rightarrow$ Analyzing errors $\rightarrow$ Explaining errors

As mentioned earlier, the researcher classified errors according to SST and according to their sources (interlingual, intralingual).

\subsection{Errors Detected in Articles}

Although there is only one indefinite article in English, 'a/an', the researcher, for the purpose of clarity, divided errors in the use of this article into two types: errors in the use of ' $a$ ' and errors in the use of 'an'. Errors in articles were categorized according to SST (substitution, omission, and addition).

Table 1. Frequency of errors according to SST

\begin{tabular}{llllllll}
\hline Error type & the & a & an & total & 'the'\% & 'a'\% & 'an'\% \\
\hline Omission & 56 & 75 & 6 & 137 & $40.9 \%$ & $54.7 \%$ & $4.4 \%$ \\
Addition & 96 & 29 & 7 & 132 & $72.70 \%$ & $22 \%$ & 5.30 \\
Substitution & 11 & 2 & 0 & 13 & $84.60 \%$ & $15.40 \%$ & $0 \%$ \\
Error total & 163 & 106 & 13 & 282 & & &
\end{tabular}

The SST as shown in Table 1 comprises three types of errors concerning the article system. The overall frequency of errors made by Saudi female EFL students is 282 errors. This result concurs with the results of other studies such as Kambel (1980), Zughul (1999), Khuwaileh and Shoumalia (2000), and Smith (2001). At first glance, the table seems to show clearly that omission errors occupy the first place according to error frequency with the percentage of $48.58 \%$. Both definite and indefinite articles were omitted in many contexts in which they must appear in well-formed sentences according to the rules of the target language. This is in line with the results of Bataineh (2005).

Further, the results also revealed that students omit the indefinite article ' $a$ ' more frequently than the other articles 'an' or 'the', as the students made 75 such errors. This result can be attributed to the fact that Arabic has no indefinite article; it is logical to conclude that the omission of the English indefinite article ' $a$ ' is attributable to Arabic interference (an interlingual error).This finding is in line with the studies of El-Sayed (1972), Smith (2001), Mourtaga (2004), and Bataineh (2005). 


\section{Examples}

....is big family.

...for student because...

...me like baby...

\section{Correction}

....is a big family.

...for a student because...

...me like a baby...

Omission of the definite article 'the' comes in second place with a frequency of 56. The researcher was surprised to discover that the omission of the definite article represents the second most frequent error type in the use of articles. The opposite was expected because Arabic uses the definite article in a wider range of contexts than English. However, it is the complicated system of the English articles, which is full of exceptions, that leaves Saudi female students uncertain whether or not to use the definite article. Hence, the errors of this type are not interlingual errors, but intralingual ones. This finding agrees with AbiSamra (2003). For example,

...in university...

...complete old habits...

Summer holiday...

\section{Correction}

...in the university...

...complete the old habits...

The summer holiday...

When using the English indefinite article, 'an' should be more difficult than 'a', due to the need to learn additional rules beyond those that apply to the article ' $a$ '. As shown in Table 1, 'an' is not used as frequently as ' $a$ '. This is why the number of errors in the use of 'an' is less than with ' $a$ '. The reason behind this might be that Arabic does not have a written indefinite article, so that Saudi females tend to omit the English indefinite article. Therefore, this error is the result of Arabicinterference (an interlingual error). This result corresponds with the findings ofSnape (2005) and Bataineh (2005).

\section{Examples}

...to talk about old Saudi family.

...interesting shopping...

...onion...

\section{Correction}

...to talk about an old Saudi family.

...an interesting shopping...

....an onion...

Of the errors, $46.80 \%$ are errors of addition. Students made different types of erroneous addition. Addition refers to the presence of an article that must not appear in a well-formed sentence in the target language. The results showed that the students use the definite article 'the' in places where it must not appear most frequently (96/132). Such a result can be related to the fact that the definite article is more widely used in Arabic as previously mentioned. When Saudi female students use the definite article excessively in English, Arabicinterference(aninterlingualerror) is the obvious explanation. This agrees with Brown (1994) and AbdelMalak (2000).

\section{Examples}

...the kabsah...

...many the family members.

I love the shopping. 
...put the rice...

\section{Correction}

...Kabsah...

...many family members.

I love shopping.

...put rice...

Moreover, the students also use the indefinite articles 'a/an' where they are not supposed to appear, but less frequently than they do the definite article 'the', as shown in Table 1 (29 and 7 out of 132 respectively). Such a result agrees with Snape (2005). Thus, this type of error is caused by the target language itself (anintralingual error). For example,

It is a Muslim country.

My country has a many...

...which are an important cities for...

...has an economic...

\section{Correction}

It is Muslim country.

My country has many...

...which are important cities for...

...has economic...

Substitution errors account for only $4.60 \%$ of errors found. This type of error was therefore made least frequently by our subjects. Students made different types of substitutions. One of the most frequent cases was the substitution of the definite article 'the' for the indefinite article ' $a$ ' as a result of interlingual error. However, in a few cases, students substituted an indefinite article ' $a$ ' for a definite article 'the' or for the zero article. This concurs with Bataineh (2005). Additionally, substitution of an indefinite article 'a' for the other indefinite article 'an' was found. This could be attributed to the target language rather than the source (an intralingual error). This finding agrees with Dulay and Burt (1974), Kim (1987), and AbiSamara (2003).

\section{Examples:}

...on the big plate...

...on the garden...

I live in the good city.

...so it was a interesting trip.

...has a many features.

\section{Correction}

...on a big plate...

...on a garden...

I live in a good city.

...so it was an interesting trip.

...has many features.

\subsection{The Sources of Article Errors}

Students' errors were classified according to their possible sources into interlingual and intralingual as mentioned earlier. In the interlingual category, the researcher was concerned with the errors that occurred as a result of the interference from elements of the L1 while using the target language. At the same time, the researcher also focused on intralingual errors, which are caused by the target language itself, and these are of different types: incomplete application of a rule, overgeneralization, and ignorance of rule restrictions. Table 2 presents the frequency of errors according to the source. 
Table 2. Frequency of errors according of sources of errors

\begin{tabular}{llllll}
\hline Error source & Omission & Addition & Substitution & total & \% of the total errors \\
\hline Interlingual & 75 & 80 & 7 & 162 & $57.4 \%$ \\
Intralingual & 62 & 52 & 6 & 120 & $42.6 \%$ \\
\hline
\end{tabular}

As shown in Table 2, most of the errors were traced to L1 interference (interlingual errors). In other words, the interlingual errors are more frequent $(57.44 \%)$ than the intralingual ones $(42.55 \%)$. This implies that the article system of the L1 (Arabic) is transferred negatively into the target language. This is in line with Mizuno (1999) and AbiSamara (2003).

\section{Examples}

In the summer...

He has a interesting stories.

...so Ha'il is city of...

\section{Correction}

In Summer...

He has interesting stories.

...so Ha'il is the city of...

The influence of L1 is clearly seen in the addition errors, of which $60.60 \%$ are interlingual. An interesting finding of this study is that the most frequent type of interlingual error committed by the students is the addition of the definite article 'the' (75). This correlates with that fact that the definite article is more widely used in Arabic, and it is this use that is transferred negatively into the target language. This concurs with the findings of Mourtaga (2004).

\section{Examples}

The Muslims...

...the black...

...the K.S.A...

\section{Correction}

Muslims...

...black...

...KSA...

Further, there is Arabic language interference in the errors of addition of the indefinite article 'an'.

\section{Examples}

....an beautiful country.

....an expensive...

\section{Correction}

...beautiful country.

...expensive...

However, in some instances, this addition has nothing to do with the L1. Of the errors in this category, 39.93\% were caused by the target language itself. This finding agrees with Kim (1987). Most of the errors of addition of the definite article ' $a$ ' are attributable to the target language rather than to the mother tongue, as shown in Table 2. Further, all the errors regarding the addition of the indefinite article 'an' are related to the target language itself. This can be attributed to the fact that the English article system is a complex aspect of English grammar. Master (2002) stated that it is one of the most difficult areas of acquisition even for the most advanced learners who have perfectly learnt all other features of the language. Another reason behind such a result might be that the Arabic language has only the one definite article ' $a l$ ' and the zero article.

\section{Examples}

An interesting places... 
...a nice stories...

...a beautiful cities...

\section{Correction}

Interesting places...

...nice stories...

...beautiful cities...

Omission errors occupy the second place among interlingual errors, as $54.74 \%$ of these errors are interlingual. This is in line with Tucker (1977). It is very clear from Table 2 that the majority of the errors regarding the omission of the indefinite articles 'a' or 'an' (50 errors out of 75 errors regarding the omission of the definite article ' $a$ ', and 5 out of 6 relating to the omission of 'an') are caused by the L1 interference. This is due to the fact that the Arabic language has only zero as an indefinite article.

Moreover, there are a number of cases of omission errors in which the target language is the source of errors: $45.25 \%$ of the omission errors are intralingual ones. The target language was the most frequent source of the omission of the definite article 'the' (36 out of 56). This finding is also confirmed by Dulay and Burt (1974) and AbiSamara (2003). In contrast the omission of the indefinite articles ' $a$ '/ 'an', when attributable to the target language, is least frequently found, as presented in Table 2.

The transfer of Arabic structures (i.e. uses of the articles) into the English of Arabic students resulted in a number of errors. Errors of substitution are few in number; most of them are related to the mother tongue language. This agrees with Snape (2005). The findings of this study show that students sometimes make errors in cases where no article is required (the zero article). In other words, when examining this type of error, it was found that most of them can be explained as a result of a negative transfer from L1. This supports the idea that L1 is one of the cognitive processes used by learners to extract the rules and principles of the target language. Interestingly, the results revealed that $53.84 \%$ of the substitution errors are interlingual ones. In most of the substitution cases, students substituted the definite article 'the' for the indefinite ' $a$ '. This finding can be related to the fact that the definite article is used more frequently in the Arabic language than in English. Another type of substitution found in this study attributable to L1 is the use of the definite article 'the' for the zero article.

\section{Examples}

...the good quality,

I think the style is...

....and the clean places,

\section{Correction}

...good quality,

I think style is...

...and clean places,

On the other hand, the target language was found to be the cause of a number of substitution errors, since $46.15 \%$ of substitution errors were intralingual errors. The study shows that students can substitute the definite article for the indefinite article or zero article, in both of which cases the target language is the cause.

\section{Examples}

There is the good city in Saudi Arabia which is...

The Summer in KSA...

...the good price...

\section{Correction}

There is a good city in Saudi Arabia which is...

Summer in KSA...

...good price...

\section{Conclusion}

This paper investigated the error types in the use of the article system by Saudi female EFL students at Ha'il 
University in Saudi Arabia. It also aimed to uncover the sources of these errors. It has been shown that the overwhelming majority of students made numerous such errors. Considering the error types, the present study reveals that errors in omission of the articles were the most frequent. Looking more closely at this type of error, omission of the indefinite article 'a/an' was committed most frequently. Further, addition errors are the second most frequent after omission errors, and the addition of the definite article 'the' seems to be the most frequent of such errors. This finding was expected as the definite article is used more frequently in the Arabic language than in English. On the other hand, the addition of the indefinite article 'an' was least frequently committed by our students. Substitution errors were found to be the least frequent. These findings can be related to the differences in the article systems of Arabic and English. Thus, teachers should focus on these differences and pay more attention to these differences, in order to reduce the number of errors caused by learners' first languages. Moreover, it is highly important to teach the definite article first, as it is the most unmarked and the most frequent, giving more attention to the indefinite articles, and presenting the central meaning of each article and comparing it with the corresponding constructions in Arabic.

The results revealed that interference is not the only source of errors made by Saudi female EFL students. In fact, English was the source of many errors as well. Specifically, the results show that L1 interference strongly influences the process of second language acquisition of articles. The students relied heavily on transfer to judge the appropriate usage of articles. Therefore, instructors have to point out the differences between L1 and L2 in the use of articles. Thus, the present study supports Brown (1980), whose idea is that interlingual errors are the most significant. This is due to the fact that while students are trying to learn a second language, they are not fully familiar with the target language's rules. The only language they are fully familiar with is their own language, so they transfer their own grammatical rules into the target language and make errors.

In fact, among the four skills of language, writing is considered to be an integral part of any language learning process. Writing requires the ability to produce thoughts and ideas in the L2, and lack of skill in writing causes many problems for learners in undertaking writing tasks in a second or foreign language. Poor writing ability is the main concern among our students, and our students are not exceptions. As English is not the means of instruction in the educational system of Saudi Arabia, the students are less exposed to English in daily or academic communication, and they are weaker at English, especially in writing skills.

Above all, it is important that one should ask why all these errors occur, and how one can get rid of them. In fact, the teaching/learning situation in Saudi Arabia reveals that Saudi students do not practice enough writing in and out of the classroom, and that the grammar rules their teachers focus on are not put into practice in actual writing. Thus, the researcher of the present study believes that sufficient practice of English writing and a proper method of teaching English grammar are the best solutions to eliminate, or at least reduce, the writing errors of Saudi students. Additionally, in order to reduce the errors students should be encouraged to speak English at home and with their friends, as well as being taught more effectively the rules and conventions of writing. Writing is a skill acquired only through practice. It is like sport, an activity that can be improved through practice (Andrews, 1999), and through 'the exposure to written text in a natural process of communication rather than grammatical and rhetorical rules on writing' (Leki, 1992, p. 17). Therefore, our students need much practice in writing. Further, it is hoped that the results of this study will enable teachers to examine their error correction practices from the learner's perspective, so that they will adjust their techniques, if necessary, to cater to the needs of their students.

Summing up, the researcher would like to restate that EFL writing instructors need to remember that students are to be treated with sensitivity and consideration. Further, they should remember that they are not error hunters, but that their job is to create a non-threatening classroom by convincing students that they can write, that writing can be learned, and that nobody's writing is perfect. Thus, criticizing students' composition should be avoided, and praising them is vital. Such praise will create trust through which we, as EFL writing instructors, will learn from our students. They have a lot to say and write. We must trust that our students will write and write and write, and it is writing that makes them feel brave, enhances self-esteem and confidence, increases positive feeling, and makes them think of themselves as writers.

The present study, like all studies, has its limitations. For instance, the subjects of the study were female only. The results would be more generalizable if both sexes were included in the study. In addition, the subjects are first-year students majoring in English selected from one university. Therefore, the findings in this research may not be generalized to other group of Saudi EFL learners. Research into the significant features of the article system and the sources of error in this area is not only an interesting and new phenomenon, but also a useful and meaningful one. The present study merely serves as one preliminary attempt. 
Researchers interested in article use may wish to see some recommendations for future research. It isrecommended to investigate a lower academic level such as intermediate school students whether in Saudi Arabia or in another country, since this might yield different results. Furthermore, it is very important to compare the results of intermediate school students with high school and university students. This study is the first of its kind to look at Saudi EFL students' use of articles. A plea is made for more research on Arabic learners in general and Saudi EFL learners in particular.

\section{References}

AbiSamra, N. (2003). An analysis of errors in Arabic speakers' English writing. In Mourtaga, K. (Ed.), Investigating writing problems among Palestinian students studying English as a foreign language. Unpublished doctoral dissertation.

Andrews, S. (1999). Writing as performance. In Graves, R. (Ed.), Writing, teaching, learning: A sourcebook (pp. 258-266). NH: Boynton/Cook Publishers, Inc.

Bataineh, R. (2005). Jordanian undergraduate EFL students' errors in the use of indefinite article. Asian EFL Journal, 7(1), 56-67.

Brown, H. (1980). Principles in language learning and teaching. New Jersey: Prentice Hall.

Brown, H. (1994). Principles of language learning and teaching (4th ed.). New York: Longman.

Bukhari, \& Hussain. (2011). Error Analysis: Learning Articles and Prepositions among Secondary School Students in Pakistan. Interdisciplinary Journal of Contemporary Research in Business, 2(12).

Butler, Y. (2002). Second language learners' theories on the use of English articles: An analysis of the metalinguistic knowledge used by Japanese students in acquiring the English article system. Studies in Second Language acquisition, 24(3), 451-480.

Corder, S. (1967). The significance of learners' errors. In Richard, J. (Ed.), Error analysis: Perspectives on second language acquisition (pp. 19-27). London: Longman.

Dulay, H., \& Burt, M. (1974). Errors and Strategies in Child Second Language Acquistion. TESOL Quarterly, 8(2), 129-136. http://dx.doi.org/10.2307/3585536

Ellis, R. (1997). SLA research and language teaching. Oxford: Oxford University Press.

El-Sayed, A. (1982). An investigation into syntactic errors of Saudi freshmen's English compositions. Doctoral dissertation, Indiana University of Pennsylvania, Pennsylvania.

Frith, B. (1977). Second Language Learning: An Examination of Two Hypotheses. IRAL, 12, 327-342.

Gass, S., \& Selinker, L. (1984). Language transfer in language learning. Rowley, MA: Newbury House.

Kambal, M. (1980). An analysis of Khartoum University Students' Composition Errors with Implications for Remedial English in the Context of Arabicization. Doctoral dissertation, University of Texas at Austin, USA.

Kharma, N., \& Hajjaj, A. (1989). Errors in English among Arabic speakers: Analysis and remedy. London: Longman Group Limited.

Khuwaileh, A., \& Shoumali, A. (2000).Writing errors: a study of the writing ability of Arab learners of academic English and Arabic at university. Language, Culture and curriculum, 13(2), 174-183.

Kim, T. (1987). Contrastive analysis, error analysis and interlanguage in relation to adult Chinese speakers learning second language. Edmonton: Linguistic Research Inc.

Lakkis, K., \& Abdel Malak, M. (2000). Understanding the transfer of prepositions: Arabic to English. In Mourtaga, K. (Ed.), Investigating writing problems among Palestinian students studying English as a foreign language. Unpublished doctoral dissertation. http://dx.doi.org/10.1080/07908310008666597

Leki, I. (1992). Understanding ESL writers: A Guide for teachers. NH: Boynton/Cook publishers, Inc.

Magnan, S. (1983). The applied linguistics cooperative: Today and Tomorrow. The Modern Language Journal, 67(4), 382-392. http://dx.doi.org/10.1111/j.1540-4781.1983.tb01520.x

Master, P. (2002). Information structure and English article pedagogy. System, 30, 331-348. $\mathrm{http} / / / \mathrm{dx}$.doi.org/10.1016/S0346-251X(02)00018-0

Mizuno, M. (1999). Interlanguage analysis of the English article system: Some cognitive constraints facing the Japanese adult learners. International Review of Applied Linguisitics in Language Teaching, 37, 127-153. 
Mukattash, L. (1978). Apilot project in common grammatical errors in Jordanian English. Interlanguage Studies Bulletin, 3(2), 250-291.

Quirk, R., Greenbaum, S., Leech, J., \& Svartvik, J. (1972). A Grammar of contemporary English. London: Longman.

Richards, J. (2002). Longman dictionary of applied linguistics. London: Oxford University Press.

Scott, M., \& Tucker, G. (1977). Error Analysis and English Language strategies of Arab Students. Language Learning, 24(1), 69-97. http://dx.doi.org/10.1111/j.1467-1770.1974.tb00236.x

Smith, B. (2001). Arabic speakers. In Swan, M., \& Smith, B. (Eds.), Learner English: a teacher's guide to interference and other problems (pp. 195-213). Cambridge: Cambridge University Press.

Snape, N. (2005). Article use in L2 English: Missing surface inflection hypothesis (MSIH) or representional deficit hypothesis (RDH)? CamLing 2005 Proceedings, 159-165.

Zughoul, M. (1991). Lexical choice: Towards writing problematic word lists. International Review of Applied Linguistics in Language Teaching, 29, 45-61. 